\title{
Surface treatment of cellulose nanocrystals (CNC): effects on dispersion rheology
}

\author{
Karin Sahlin • Lilian Forsgren • Tobias Moberg • Diana Bernin • \\ Mikael Rigdahl $\mathbb{D} \cdot$ Gunnar Westman
}

Received: 28 June 2017 / Accepted: 15 November 2017/Published online: 28 November 2017

(C) The Author(s) 2017. This article is an open access publication

\begin{abstract}
Cellulose nanocrystals (CNC) were surface modified by grafting azetidinium salts onto the sulphate ester groups on the cellulosic surfaces. The modified CNC were characterized using NMR, FTIR spectroscopy, conductometric titration and measurement of the $\zeta$-potential. Thermal gravimetrical analysis revealed that the onset temperature for the thermal degradation was shifted upwards by almost $100{ }^{\circ} \mathrm{C}$ as a result of the surface grafting. The rheological properties of dispersions based on unmodified and
\end{abstract}

Karin Sahlin and Lilian Forsgren have contributed equally.

Electronic supplementary material The online version of this article (https://doi.org/10.1007/s10570-017-1582-5) contains supplementary material, which is available to authorized users.

K. Sahlin · G. Westman $(\bowtie)$

Department of Chemistry and Chemical Engineering, Chalmers University of Technology, Gothenburg, Sweden e-mail: westman@chalmers.se

\section{Forsgren - T. Moberg · M. Rigdahl}

Department of Industrial and Materials Science, Chalmers University of Technology, Gothenburg, Sweden

\section{Bernin}

Swedish NMR Centre, University of Gothenburg,

Gothenburg, Sweden

K. Sahlin · T. Moberg · M. Rigdahl · G. Westman Wallenberg Wood Science Center, Chalmers University of Technology, Gothenburg, Sweden modified CNC were evaluated in detail. Two solids contents were studied; 0.65 and $1.3 \mathrm{wt} \%$. In general, the grafting of the salts significantly increased the shear viscosity at a given shear rate as well as the storage and loss moduli of the dispersions. The CNC concentration at the gel point (network formation) decreased in a corresponding manner when the nanocellulosic particles were surface modified. This may be associated with pronounced hydrophobic attractive interactions between the grafted substituents.

Keywords Cellulose nanocrystals · Azetidinium salts - Chemical modification - Dispersion rheology · Thermal stability

\section{Introduction}

Cellulose nanocrystals (CNC) are an interesting class of materials in view of their combination of properties and features such as being light weight, biodegradable, originating from a renewable source, having a large surface area and possessing potentially interesting and promising mechanical properties. Regarding the mechanical properties, Lee et al. (2014) summarised some literature reports on theoretical predictions of the axial modulus of a cellulose crystal to be in the range of 58-180 GPa and the corresponding prediction of 
the tensile strength region was $0.3-22 \mathrm{GPa}$. Values of such magnitude certainly account for the interest in $\mathrm{CNC}$ as reinforcing elements in composite materials, cf e.g. Klemm et al. (2011).

The CNC can be obtained by acid hydrolysis of cellulosic fibres/fibrils to remove the amorphous parts of the cellulosic material, cf e.g. (Beck-Candanedo et al. 2005; Rånby 1951), The common cellulose source for CNC is wood but other sources such as annual plants and tunicates have also been used for CNC production (Klemm et al. 2011; Moon et al. 2011). The length of a CNC can typically be a few hundred $\mathrm{nm}$ with a width between 3 and $20 \mathrm{~nm}$ (Chauve and Jean 2014; Herrera et al. 2012). Sulphuric acid is commonly used for the hydrolysis of the cellulose fibres/fibrils and this converts some of the surface hydroxyl groups on the CNC to negatively charged sulphate ester units (Beck-Candanedo et al. 2005). The charged groups contribute to the stability of the aqueous $\mathrm{CNC}$ dispersion, i.e. reduce the tendency for particle aggregation. On the other hand, it is known that acid sulphate groups promote thermal degradation of the CNC which is associated with a dehydration reaction (Roman and Winter 2004; Wang et al. 2007). The degradation can commence already at $150{ }^{\circ} \mathrm{C}$, and this is in some cases detrimental if the $\mathrm{CNC}$ are to be incorporated into a thermoplastic matrix using conventional melt processing techniques. High performance engineering polymers usually require higher processing temperatures. For example, typical processing temperatures for polypropylene are between 210 and $250{ }^{\circ} \mathrm{C}$ and for poly(ethylene terephthalate) about $260{ }^{\circ} \mathrm{C}$ (Brydson 1999).

However, the thermal stability of the CNC can be improved by desulphation, by neutralization by an alkaline solution (Wang et al. 2007) or by reacting the sulphate groups with a suitable compound. For use in composite materials, the latter approach can provide an advantage in that the reacting group can be tailored to improve the compatibility between the CNC and the, often hydrophobic, polymeric matrix. Deionization of the sulphate groups may also affect the dense self-aggregation of the $\mathrm{CNC}$ and result in a more homogeneous blend of matrix and CNC. In the present work, it is shown that functionalization of the CNC produced by sulphuric acid hydrolysis with azetidinium salts can lead to a significant improvement in thermal stability. In a later publication, the properties of polymer matrix composites containing the modified $\mathrm{CNC}$ will be presented and discussed.

The use of azetidinium salt as a reagent for modification is a relative unexplored area. An example is the report by Chattopadhyay et al. (2012) and the salt is most probably together with epichlorohydrin a reactive group in the wet-strength agent polyamideamine-epichlorohydrin (PAE). In the review by Espy (1995) it is stated that alcohol groups may play a part in cross-linking reactions as well as carboxylate end groups of cellulosic polymers. Other reports of the chlorohydrin-azetidinium salts reactivity in PAE are that carboxymetylated cellulose (CMC) or other carboxyl-bearing polymers showed an increased effectiveness in reaction with PAE (Siqueira et al. 2015). Also, Obokata and Isogai (2007) have commented in their study on PAE that TEMPO-oxidized cellulose under alkaline conditions showed an increased reactivity toward PAE resulting in increased wet strength in cellulose sheets. However, none of these publications clearly state that the azetidinium salt is the reactive species. The functionalization of chlorohydrins on CNC to increase the hydrophobicity and enhance their dispersion in low density polyethylene has been reported by Gårdebjer et al. (2016) but neither rheological nor any temperature stability measurements were reported in their study. That azetidinium salts react with carboxylic acids has been shown by Börjesson and Westman (2016) who esterified oxidized hemicelluloses with azetidinium salts in DMSO at $90{ }^{\circ} \mathrm{C}$. It has been reported by several groups that ionic complexes, non-covalent complexes, are formed with tetraalkyl ammonium salts with CNC (Dong and Gray 1997; Ahola et al. 2008; Aloulou et al. 2004; Cranston and Gray 2006). All of these studies where performed at $60{ }^{\circ} \mathrm{C}$ or lower reaction temperatures. The present study shows that azetidinium salts react with sulphate groups, similar to carboxylic acid groups.

The rheological properties of CNC-based systems are of great importance, both from a characterization point of view and for the processing of such systems using different techniques. Such processing may involve either a simple aqueous CNC dispersion or a combination of polymers, thermoplastics or polymer solutions, and CNC. In the latter case, an understanding of the rheological properties of the aqueous dispersion can be of great importance, since the manufacture of such materials may involve combining 
the polymer with an aqueous $\mathrm{CNC}$ dispersion of an appropriate concentration in order to avoid excessive aggregation and thus poor dispersion of the CNC elements in the polymer matrix. Processing of such materials are normally associated with appreciable shear and deformation rates and it is important that the rheological properties are evaluated at such relevant deformation rates (as aimed for here). It is known that CNC dispersions can exhibit a complex rheological behaviour in the sense that they are shear thinning, show a gel-like behaviour and possess a viscoelastic character (Bercea and Navard 2000; Moberg et al. 2017; Shafiei-Sabet et al. 2012). In addition to the particle concentration, the rheological profile of a CNC dispersion is to a large extent governed by the dimensions of the nanocellulosic entities and their surface characteristics (Moberg et al. 2017; ShafieiSabet et al. 2013). In addition, the CNC can form liquid crystalline domains which can affect the flow behaviour depending on the concentration and shear rate (Bercea and Navard 2000; Shafiei-Sabet et al. 2012). For example, Shafiei-Sabet et al. (2012) measured the shear viscosity as a function of shear rate and found that, in a certain concentration region, the viscosity profile could be divided into three regions depending on the shear rate and the formation of chiral nematic liquid crystalline domains. At low shear rates, the viscosity decreased with increasing shear rate, which was attributed to an alignment of these domains, an intermediate region was characterized by a plateau in the viscosity curve where all the domains had been oriented in the flow direction, and at high shear rates ( $>$ than ca $10 \mathrm{~s}^{-1}$ in their work) a second region was found where the viscosity again decreased with increasing shear rate, which was suggested to be associated with the disruption of the liquid crystalline domains. Recently the effect of electrolytes and changes in surface chemistry on the rheological properties (mainly in shear) of $\mathrm{CNC}$ dispersions as well as their behaviour in dilute polymer solutions were reviewed by Oguzlu et al. (2017). Of special interest in this context may be that Hasani et al. (2008) reported quite dramatic effects (i.e. an increase) on the shear viscosity of $\mathrm{CNC}$ dispersions when the $\mathrm{CNC}$ particles were surface functionalized with cationic hydroxypropyltrimethylammonium chloride substituents.

A focus of the present work has been to assess the effect of functionalization of the $\mathrm{CNC}$ with azetidinium salts on the viscosity, the gel point and the viscoelastic properties of the dispersions at rather low particle concentrations ( 0.65 and $1.3 \mathrm{wt} \%)$. As pointed to, surface treatments of this kind can improve the thermal stability of the nanocellulose and also provide a starting point for an enhanced compatibility between the cellulosic particles and a polymer matrix leading to an improved dispersion of the reinforcing elements in the polymer and thus a corresponding improvement in the physical properties of the composite material in the solid state. The effect on the properties of a composite material will however be the subject of a subsequent study. The present study indicates that surface modification of the $\mathrm{CNC}$ with azetidinium salts resulted in a substantial increase in the viscosity level and in the dynamic-mechanical moduli and quite a drastic lowering of the gel point. The results are discussed in terms of interactions between the grafted substituents related to their lipophilic character.

\section{Experimental}

Materials

CNC suspensions were prepared from microcrystalline cellulose (MCC) by a sulphuric acid treatment according to the procedure described by Hasani et al. (2008) with adjustments based on raw material and scale-up. An aqueous dispersion of cellulose nanocrystals was prepared by hydrolysis of $500 \mathrm{~g} \mathrm{MCC}$ using $4.37 \mathrm{~L}$ $64 \mathrm{wt} \%$ (weight $\%$ ) sulphuric acid continuously stirred at $45{ }^{\circ} \mathrm{C}$ for $2 \mathrm{~h}$. The reaction was quenched by dilution in $4 \mathrm{~L}$ deionized water immediately followed by dialysis against deionized water until the conductivity of the effluent was below $5 \mu \mathrm{S}$. The CNC particles were dispersed by sonication with a Sonics vibracell $500 \mathrm{~W}$ equipped with a standard probe with tip diameter of $13 \mathrm{~mm}$ operating at $40 \%$ of maximum amplitude for $6 \mathrm{~min}$, repeated 7 times, until a colloidal dispersion was achieved. Moberg et al. (2017) using atomic force microscopy found that the average length of the crystals prepared in a similar manner was $211 \pm 114 \mathrm{~nm}$ and their average width $6.0 \pm 1.5 \mathrm{~nm}$.

The CNC were surface modified by grafting three different chemical groups onto the cellulose surface; $\mathrm{N}$-morpholino-3-methoxyazetidinium, N,N-dihexyl3-methoxyazetidinium and N,N-diallyl-3- 
methoxyazetidinium. These modifications are here denoted MorphOMe, diHexylOMe and diAllylOMe, respectively. The grafting was performed using substituted azetidinium salts following a procedure outlined by Chattopadhyay et al. (2012). By adding these azetidinium salts to CNC dispersed in a DMSOtoluene mixture, the azetidinium ion reacts with the sulphate groups on the CNC surface. Prior to the reaction, a solvent exchange to DMSO was done for the aqueous $\mathrm{CNC}$ dispersion through an azeotrope with toluene to prevent the azetidinium salts from undergoing dimerization to 2,5-bis(disubstituted)-1,4dioxanes, which can occur in aqueous alkali (Gaertner 1968). An excess of $\mathrm{N}, \mathrm{N}$-disubstituted azetidinium salts (3 mol equiv/anhydroglucose unit) was then added to the CNC dispersed in a DMSO-toluene mixture (90:10 ratio) in a round-bottomed flask and the reaction was stirred at $90{ }^{\circ} \mathrm{C}$ for $22 \mathrm{~h}$. The reaction mixture was then allowed to cool to room temperature and subsequently washed with acetonitrile, ethanol and deionized water in that order through repeated centrifugation steps. It has been shown that the surface treatments do not significantly change the dimensions of the CNC particles (Hasani et al. 2008).

Preparation of N,N-disubstituted azetidinium salts

The azetidinium salts were prepared following procedures described in the literature (Chattopadhyay et al. 2012) with some modifications. The general procedure consisted of dropwise adding one mole equivalent of epichlorohydrin to a solution of one mole equivalent of secondary amine and solvent. Due to the exothermic nature of the reaction between epichlorohydrin and the secondary amine, the temperature was kept below $5{ }^{\circ} \mathrm{C}$ during the addition of the epichlorohydrin. The reaction was then stirred continuously for 2-4 days at room temperature before the solution was extracted using diethyl ether and subsequently washed in water followed by removal of the solvent under vacuum.

For the synthesis of N-morpholino-3-hydroxyazetidinium chloride ${ }^{1}$ (MorphOH-Az), morpholine was used as secondary amine and the solvent used was water, for the synthesis of N,N-dihexyl-3-hydroxyazetidinium chloride (diHexylOH-Az), dihexylamine was

\footnotetext{
${ }^{1}$ IUPAC name: 7-Oxa-4-azoniaspiro[3.5]nonane, 2-hydroxy-, chloride.
}

used as secondary amine and the solvent use was hexane, and for the synthesis of N,N-diallyl-3-hydroxyazetidium chloride (diAllylOH-Az), diallylamine was used as secondary amine and acetonitrile was used as solvent. Unpublished results from our lab have found that there is not a solvent that gives high yield of azetidinium salt independently of dialkyl amine used. Therefore, three different solvent has been used in the above-mentioned reactions. The products were verified by NMR.

MorphOH-Az ${ }^{1} \mathrm{H} \quad$ NMR (DMSO- $d_{6}, 400 \mathrm{MHz}$ ) 6.64, (bs, 1H), 4.62, (m, 1H), 4.54, (dd, $J=4 \mathrm{~Hz}$, $2 \mathrm{H}), 4.20,(\mathrm{dd}, J=4 \mathrm{~Hz}, 2 \mathrm{H}), 3.76$ (t, $J=4 \mathrm{~Hz}, 4 \mathrm{H})$, 3.60, (t, $J=4 \mathrm{~Hz}, 2 \mathrm{H}), 3.49$ (t, $J=4 \mathrm{~Hz} 2 \mathrm{H})$.

DiAllylOH-Az ${ }^{1} \mathrm{H}$ NMR (DMSO- $d_{6}, 400 \mathrm{MHz}$ ) 6.62, (bs, 1H), 5.97, (m, 2H), 5.63, (m, 4H), 4.61, $(\mathrm{m}, 1 \mathrm{H}), 4.43,(\mathrm{~m}, 2 \mathrm{H}), 4.22,(\mathrm{~m}, 2 \mathrm{H}), 4.09(\mathrm{~d}, J=$ $4 \mathrm{~Hz}, 2 \mathrm{H}), 3.94$, (d, $J=4 \mathrm{~Hz}, 2 \mathrm{H})$.

DiHexylOH-Az ${ }^{1} \mathrm{H}$ NMR (DMSO- $d_{6}, 400 \mathrm{MHz}$ ) 6.38, $(\mathrm{d}, J=4 \mathrm{~Hz}, 1 \mathrm{H}), 4.59$, (m, $1 \mathrm{H}), 4.40$, (dd, $J=8,12 \mathrm{~Hz}, 2 \mathrm{H}), 4.06$, (dd, $J=4,12 \mathrm{~Hz}, 2 \mathrm{H}), 3.74$ $(\mathrm{m}, 2 \mathrm{H}), 3.61,(\mathrm{~m}, 2 \mathrm{H}), 1.47(\mathrm{~m}, 4 \mathrm{H}), 1.24(\mathrm{~m}, 12 \mathrm{H})$, $0.84(\mathrm{t}, J=6 \mathrm{~Hz}, 6 \mathrm{H})$.

Preparation of N,N-disubstituted-3-methoxy azetidinium salts

Potassium-t-butoxide was added to the N,N-disubstituted azetidinium salt dissolved in dichloromethane, methyl tosylate was added after 2 min and the reaction was stirred at room temperature for $1 \mathrm{~h}$. A small amount of water $(10 \mathrm{~mL})$ was added to quench the reaction. The mixture was concentrated under reduced pressure followed by trituration with acetonitrile, to obtain the crude product, and then concentrated again under reduced pressure.

For the synthesis of N-morpholino-3-methoxyazetidinium chloride $^{2}$ (MorphOMe-Az), $1.2 \mathrm{~g}(11 \mathrm{mmol})$ potassium-t-butoxide was mixed with $1.8 \mathrm{~g}$ (10 mmol) of MorphOH-Az in $10 \mathrm{ml}$ dichloromethane and $2.2 \mathrm{~g}$ (12 mmol) methyl-p-toluenesulphonic acid was added after a few minutes. The procedure and amounts for the synthesis of diHexylOMe-Az, and diAllylOMe-Az were the same as for

\footnotetext{
${ }^{2}$ IUPAC name: 7-Oxa-4-azoniaspiro[3.5]nonane, 2-methoxy-, chloride.
} 
the synthesis of MorphOMe-Az, with the exception of the weight of the salts; $2.8 \mathrm{~g}(10 \mathrm{mmol})$ of diHexylOH-Az and $2.2 \mathrm{~g}(10 \mathrm{mmol})$ diAllylOH-Az.

The products were verified by NMR.

MorphOMe-Az (p-toluenesulphanate as counter ion) ${ }^{1} \mathrm{H}$ NMR (DMSO- $\left.d_{6}, 400 \mathrm{MHz}\right) 7.46$, (d, $J=8 \mathrm{~Hz}, 2 \mathrm{H}), 7.10,(\mathrm{~d}, J=8 \mathrm{~Hz}, 2 \mathrm{H}), 4.55$, (dd, $J=8.12 \mathrm{~Hz}, 1 \mathrm{H}), 4.26$, (bt, 2H), 4.54, (dd, $J=4 \mathrm{~Hz}$, $2 \mathrm{H}), 4.20,(\mathrm{dd}, J=4 \mathrm{~Hz}, 2 \mathrm{H}), 3.76(\mathrm{t}, J=4 \mathrm{~Hz}, 4 \mathrm{H})$, $3.60,(\mathrm{t}, J=4 \mathrm{~Hz}, 2 \mathrm{H}), 3.49$ (t, $J=4 \mathrm{~Hz} 2 \mathrm{H}), 2.27$ (s, $3 \mathrm{H})$.

IR (KBr tablet) 564, 676, 816, 1004, 1032, 1116, 1190,2941 and $3430 \mathrm{~cm}^{-1}$.

DiAllyl-OMeAz (p-toluenesulphanate as counter ion) $\left(\mathrm{DMSO}_{-}, 400 \mathrm{MHz}\right) 7.46,(\mathrm{~d}, J=8 \mathrm{~Hz}$, $2 \mathrm{H}), 7.09,(\mathrm{~d}, J=8 \mathrm{~Hz}, 2 \mathrm{H}), 6.04,(\mathrm{~m}, 2 \mathrm{H}), 5.62$, (broad dd 4H), $5.01(\mathrm{~b} 1 \mathrm{H}), 4.01$ broad $(\mathrm{m}, 4 \mathrm{H}), 3.33$ (s, 3H), 2.27 (s, 3H).

IR (KBr tablet) 568, 683, 693, 812, 1008, 1039, $1127,1182,1717,2980$ and $3437 \mathrm{~cm}^{-1}$.

DiHexylOMe-Az (p-toluenesulphanate as counter ion) ${ }^{1} \mathrm{H}$ NMR (DMSO- $\left.d_{6}, 400 \mathrm{MHz}\right) 7.46$, (d, $J=8 \mathrm{~Hz}, 2 \mathrm{H}), 7.09$, (d, $J=8 \mathrm{~Hz}, 2 \mathrm{H}), 4.45$, (dd, $J=8.12 \mathrm{~Hz}, 1 \mathrm{H}), \quad 4.29, \quad(\mathrm{~m}, 1 \mathrm{H}), 4.15, \quad(\mathrm{dd}$, $J=8.12 \mathrm{~Hz}, 1 \mathrm{H}), 3.80,(\mathrm{~b}, 2 \mathrm{H}), 3.30(\mathrm{~m}, 4 \mathrm{H}), 3.10$, $(\mathrm{m}, 1 \mathrm{H}), 2.27(\mathrm{~s}, 3 \mathrm{H}) 1.47(\mathrm{~m}, 4 \mathrm{H}), 1.26(\mathrm{~m}, 12 \mathrm{H}), 0.86$ (t, $J=6 \mathrm{~Hz}, 6 \mathrm{H})$.

IR ( $\mathrm{KBr}$ tablet) 560, 670, 680, 812, 1011, 1025, 1046, 1123, 1179, 1219, 2930 and $3461 \mathrm{~cm}^{-1}$.

Model reaction using 2-methyl-2-propene-1sulphonic acid

In order to check whether the sulphonate groups on $\mathrm{CNC}$ can react with the azetidinium salts, reference materials were prepared by reacting a sulphonic acid with two of the prepared azetidinium salts. 2-methyl2-propene-1-sulphonic acid $(1.58 \mathrm{~g}, 10 \mathrm{mmol})$ was mixed with $\mathrm{N}$-morpholino-3-methoxyazetidinium chloride $(1.93 \mathrm{~g}, 10 \mathrm{mmol})$ or N,N-dihexyl-3methoxyazetidinium chloride $(2.91 \mathrm{~g}, 10 \mathrm{mmol})$ in a DMSO-toluene mixture (90:10 ratio) in a roundbottomed flask and the reaction was stirred at $90{ }^{\circ} \mathrm{C}$ for $22 \mathrm{~h}$. The reaction mixture was then allowed to cool to room temperature. Upon cooling, the product precipitated and it was subsequently washed with diethyl ether and dried at room temperature.

In order to clarify whether the effect of the added substituents on the rheological behaviour of the dispersions was the result of the grafting or simply due to the presence of the ring-opened azetidinium reagents, unmodified $\mathrm{CNC}$ was mixed with the two model compounds ( $\gamma$-N,morpholino- $\beta$-methoxypropyl or $\gamma$-N,N-dihexylamino- $\beta$-methoxypropyl). The model compounds were mixed with the aqueous dispersions of the unmodified $\mathrm{CNC}$ in a ratio corresponding to a degree of substitution on the sulphate groups of 90 per cent. The shear viscosity of these dispersions were then evaluated as a function of the shear rate.

Characterization methods

Salt formation and model reaction results were verified by solution NMR on a Varian MR-400 (400 MHz) operating at $399.95 \mathrm{MHz}$ for proton detection and $100.58 \mathrm{MHz}$ for carbon detection. DMSO- $\mathrm{d}_{6}$ was used as solvent for all the samples.

Solid-state NMR analysis of the azetidinium substituted CNC was performed on a 14.7 T Agilent Inova $\left({ }^{13} \mathrm{C}\right.$ and ${ }^{1} \mathrm{H}$ Larmor frequency of -150.9 and - 600.1 MHz) fitted with a $3.2 \mathrm{~mm}$ double-resonance MAS probe. ${ }^{13} \mathrm{C}$ cross polarization $(\mathrm{CP})$ were recorded at a spinning speed of $9 \mathrm{kHz}$. The ${ }^{13} \mathrm{C}$ spectral width was set to $30.48 \mathrm{kHz}$, the repetition delay was $3.3 \mathrm{~s}$ and spinal decoupling was used in all cases. The cross polarization time was set to $1 \mathrm{~ms} .8192$ signal accumulations were recorded for each experiment.

The $\zeta$-potential was measured for all CNC samples using a Zetasizer Nano ZS (Malvern Instruments, UK) based on the Laser Doppler Velocimetry technique. The light source was a $50 \mathrm{~mW}$ diode-pumped solidstate laser with a wavelength of $532 \mathrm{~nm}$. All measurements were carried out at $25{ }^{\circ} \mathrm{C}$ using DTS1070 disposable folded capillary cells. The samples were stabilized for $120 \mathrm{~s}$ inside the device and five measurements per sample were recorded with 5 runs per measurement and three replicates. Samples were prepared by dilution to $0.05 \mathrm{wt} \%$ dry content and adjustment of the $\mathrm{pH}$ to 3.5 followed by ion exchange (Dowex ${ }^{\circledR}$ Marathon ${ }^{\mathrm{TM}}$ MR-3 hydrogen and hydroxide 
form) overnight and subsequent removal of resin beads by filtration.

The sulphate half ester content was determined using conductometric titration (Eutech Instruments, Singapore). Typically, a sample volume of $100 \mathrm{ml}$ $0.1 \mathrm{wt} \% \mathrm{CNC}$ dispersion was prepared and initially $\mathrm{pH}$-adjusted to a value below 3.5 by addition of $0.1 \mathrm{M}$ hydrochloric acid to ensure that all sulphate groups were in their hydrogen form. The conductivity was then measured while 0.1 or $0.2 \mathrm{~mL}$ of $0.01 \mathrm{M}$ sodium hydroxide was added at $60 \mathrm{~s}$ intervals until a $\mathrm{pH}$ value of 11 was reached. The sulphate half ester content was determined from the volume of sodium hydroxide required for neutralisation of strong acids, deducting the amount needed for the added hydrochloric acid.

Fourier-Transform Infrared (FTIR) spectroscopy was performed with a Perkin Elmer Spectrum One instrument using the potassium bromide $(\mathrm{KBr})$ pellet technique with freeze-dried CNC samples. FTIR spectra were determined between 4000 and $400 \mathrm{~cm}^{-1}$ and 32 scans were collected.

Thermal gravimetrical analysis (TGA) was used to determine the onset of thermal degradation of the CNC samples and was measured using a TGA/DSC $3+$ Star system (Mettler Toledo, Switzerland). A $5{ }^{\circ} \mathrm{C} / \mathrm{min}$ heating rate was used to heat an approximately $10 \mathrm{mg}$ sample from 25 to $500{ }^{\circ} \mathrm{C}$ under nitrogen at a flow rate of $20 \mathrm{~mL} \mathrm{~min}^{-1}$.

The rheological measurements on the dispersions were carried out at $25{ }^{\circ} \mathrm{C}$ and at two concentrations (0.65 and $1.3 \mathrm{wt} \%$ ) with an Anton Paar MCR 702 rheometer (Graz, Austria) using a cone-plate configuration (cone diameter $50 \mathrm{~mm}$ and cone-plate angle $1.991^{\circ}$ ). The concentration of the $\mathrm{CNC}$ dispersions was initially somewhat higher, but was diluted to the target concentrations with deionized water. Both the shear viscosity and the dynamic shear properties, given by the storage modulus $G^{\prime}$ and the loss modulus $G^{\prime \prime}$, were determined. The steady state shear viscosity was determined at shear rates between 1 and $1000 \mathrm{~s}^{-1}$. The dynamic-mechanical properties were measured during a strain sweep at $1 \mathrm{~Hz}$ in which the moduli $G^{\prime}$ and $G^{\prime \prime}$ were measured as functions of the applied shear strain amplitude. For each sample, the measurements were, in most cases, repeated three times (using different specimens) and the variation in shear viscosity and storage modulus between the specimens was less than $15 \%$ (standard deviation).

\section{Results and discussion}

Characterisation of the chemical modification

The successful preparation of the azetidinium salts was verified with ${ }^{1} \mathrm{H}$ and ${ }^{13} \mathrm{C}$ NMR. Ring closed 2-hydroxyazetidnium salts have a characteristic signal for the $\mathrm{OH}$-group at approximately $6.0 \mathrm{ppm}$, the $\mathrm{C} 2$ and $\mathrm{C}^{\prime}$ have signals in the $4.0-4.6 \mathrm{ppm}$ region and usually two sets of alkyl groups signals, even though they are identical. This is because the two alkyl groups are sitting on a ring that can have two different conformations and as a consequence provide different environments for the alkyl substituents.

The successful grafting of the azetidinium reagents on the CNC was confirmed using solid state NMR, FTIR, $\zeta$-potential, conductometric titration, and TGA as discussed in the following.

As a complement to FTIR, $\zeta$-potential and conductometric titration, the modified $\mathrm{CNC}$ were analysed with solid state MAS NMR using cross-polarization (CP). Figure 1 shows the ${ }^{13} \mathrm{C} \mathrm{CP}$ spectra of the $\mathrm{CNC}$ derivates with the peak pattern typically observed between 60 and $110 \mathrm{ppm}$, which shows that all the samples had a similar crystallinity after the treatment. Due to the high glucose: substituent ratio of approximately 50:1, the ${ }^{13} \mathrm{C} \mathrm{CP}$ signals from the substituents between 10 and $40 \mathrm{ppm}$ are extremely weak.

Both modified and unmodified samples were analysed with FTIR, and the spectra are shown in Fig. 2. All three of the azetidinium salts had p-toluenesulphonate as counter ion (spectra in Supplementary information). The p-toluenesulphonate group has the characteristic $\mathrm{SO}_{3}$-vibrations at approximately 570, 690, 1015, 1032, 1185 and $1200 \mathrm{~cm}^{-1}$ (Shishlov and Khursan 2016). For the different substituents, the diHexylOMe-Az has the strongest $\mathrm{CH}$-vibrations in the 2800-3100 $\mathrm{cm}^{-1}$ region, whereas the MorphOMeAz has the broadest signals and the diAllylOMeAz has the weakest signals as expected from the number of carbons in the respective salts. At $1250 \mathrm{~cm}^{-1}$ is also a signal for the distorted azetidinium cation, a signal that becomes less intense upon ring opening of the azetidinium salt (Gurziy et al. 2018). Also the 
a)

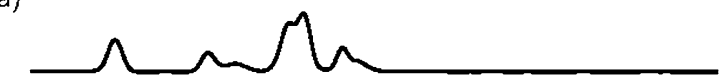

b)

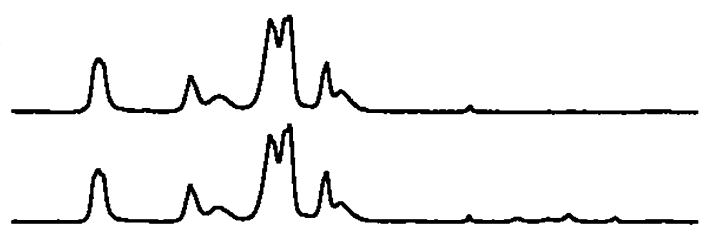

d)

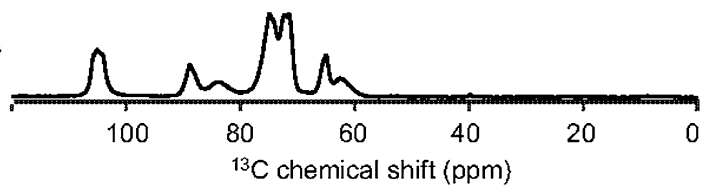

Fig. $1{ }^{13} \mathrm{C}$ CP MAS spectra of CNC-derivatives a unmodified $\mathrm{CNC}$ as a reference b MorphOMe-Az, c DiHexylOMe-Az, d DiAllylOMe-Az

p-toluenesulphonate counter ion disappear upon conjugation of the azetidinium salt to the CNC surface.

All the samples showed the typical adsorption peaks of cellulose I (Ciolacu et al. 2011). The broad band at $3600-3000 \mathrm{~cm}^{-1}$ corresponds to the characteristic-OH stretching from vibrations in the intra-and intermolecular hydrogen-bonded hydroxyl groups in cellulose I. The band at $2901 \mathrm{~cm}^{-1}$ is attributed to aliphatic saturated $\mathrm{CH}$-stretching in the glucose units. Other peaks detected include the adsorption band at $1640 \mathrm{~cm}^{-1}$ which is attributed to water absorbed onto cellulose, the peak at $1430 \mathrm{~cm}^{-1}$ associated with $\mathrm{CH}_{2}$ scissoring motion and symmetrical bending in cellulose $\mathrm{I}$, the peak at $1164 \mathrm{~cm}^{-1}$ corresponding to the asymmetrical bridge $\mathrm{C}-\mathrm{O}-\mathrm{C}$ stretching from the glycosidic bond, the band at $1112 \mathrm{~cm}^{-1}$ representing stretching of the glucopyranose unit and the peak at $898 \mathrm{~cm}^{-1}$ typical of the $\beta$-glycosidic linkage in cellulose I. It is difficult to discern any clear differences in the FTIR spectra between the modified and the unmodified samples since substitution occurs on the sulphate groups and the amount of anhydrous glucopyranose is therefore far greater than the amount of grafted-on azetidinium. There are some changes worth highlighting, the first is for conjugation, functionalization of $\mathrm{CNC}$ with azetidinium salt. In the unmodified CNC sample, there is a small peak at $815 \mathrm{~cm}^{-1}$ corresponding to symmetric stretching of the sulphate ester linkages (S-O-C) (Chen et al. 2013), that shifts to $796 \mathrm{~cm}^{-1}$ in the modified samples. This indicates a substitution with an electropositive substituent on the sulphate ester, resulting in the formation of a sulphate diester, supporting the

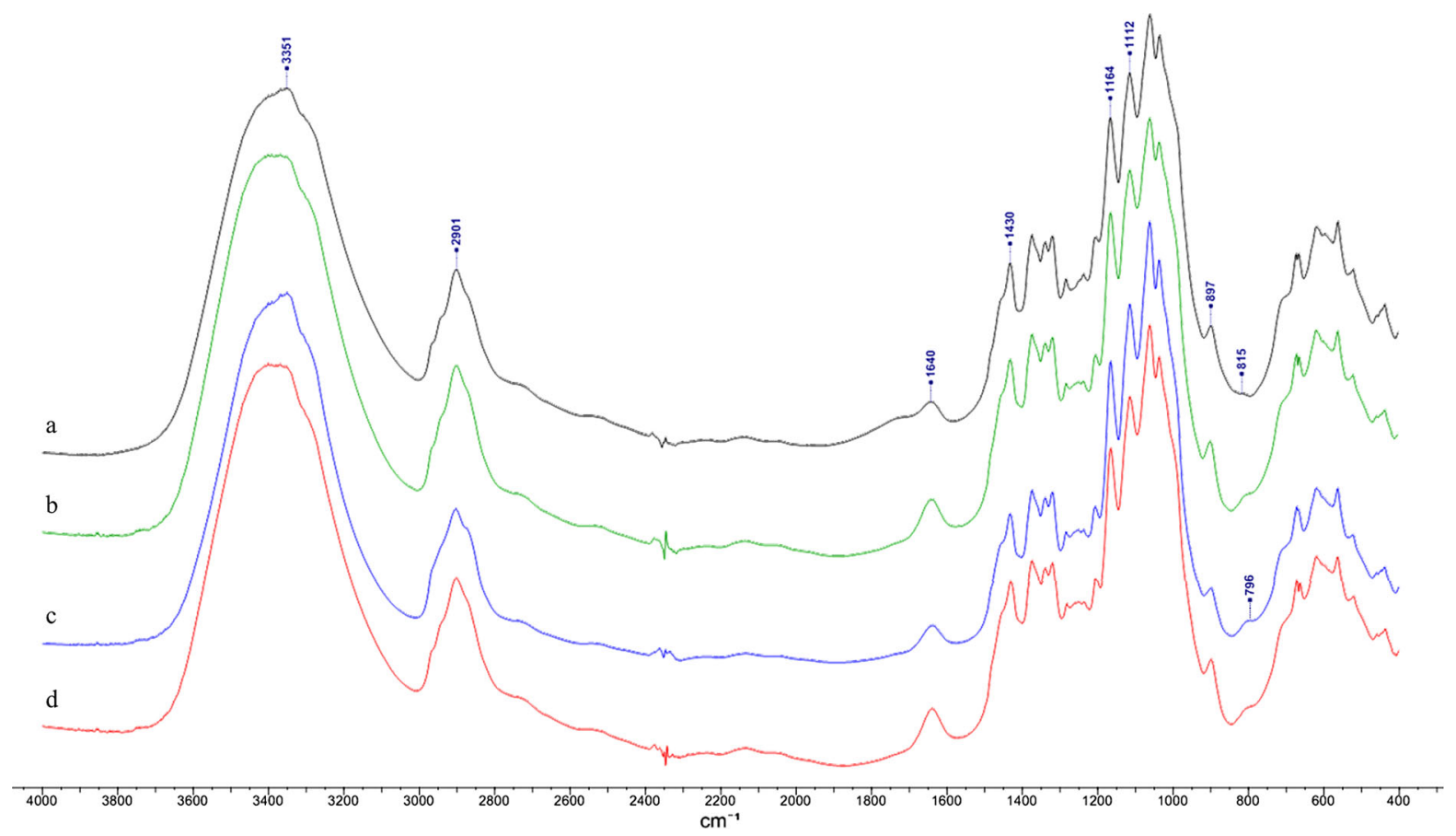

Fig. 2 FTIR spectra of a the unmodified CNC and b MorphOme-Az, $\mathbf{c}$ diHexylOMe-Az, and d diAllylOMe-Az-grafted CNCs 
conclusion that grafting of an azetidinium salt has occurred. A slight difference can also be observed at around $1262 \mathrm{~cm}^{-1}$, where a new peak appeared upon modification, it is within the medium to weak band for $\mathrm{C}-\mathrm{N}$ stretching of tertiary amines and thus corresponding to the tertiary amine introduced by the azetidinium reagent. Then for the MorphOMe substituted CNC, Fig. 2b, there are hard to see any additional changes which is not unexpected since the Morph substituent adds already existing $\mathrm{C}-\mathrm{H}, \mathrm{C}-\mathrm{C}$ and $\mathrm{C}-\mathrm{O}$ frequencies to the $\mathrm{CNC}$ sample. For the diHexylOMe CNC, Fig. 2c, there an increased intensity of the region $2800-3000 \mathrm{~cm}^{-1}$, the are characteristic for $\mathrm{C}-\mathrm{H}$ stretching, thus implying increased number of $\mathrm{C}-\mathrm{H}$ in the $\mathrm{CNC}$. For the diAllylOMe a broadening at 1650 is observed which correlates to $\mathrm{C}=\mathrm{C}$ frequencies.

The $\zeta$-potential and the sulphate half ester content of the CNC-particles are given in Table 1. Not unexpectedly, the lowest $\zeta$-potential was noted for the unmodified $\mathrm{CNC}$, which is attributed to the sulphuric groups on the cellulose surface. The grafting of the azetidinium reagents increased the $\zeta$-potential and the highest value $(\mathrm{ca}-45 \mathrm{mV})$ was noted for the CNC-MorphOMe. The same trend can be observed for the sulphate group content, i.e. the surface charge decreased upon grafting. Higher $\zeta$-potential values and lower sulphate group contents are expected for the modified samples since the azetidinium reagents react with the negatively charged sulphate groups, lowering the negative charge on the surface.

Figure 3 and Table 2 summarize the results of the TGA-measurements on the unmodified CNC and on the surface-modified particles. The most striking feature of the graph is the main onset of degradation which occurred at significantly higher temperatures for surface-modified particles, at $240-250{ }^{\circ} \mathrm{C}$. The weight-loss curve for the unmodified $\mathrm{CNC}$ clearly consists of two regions, in agreement with the literature (Kim et al. 2001; Wang et al. 2007). A similar tendency can be discerned in the curves for the modified CNC, although it is much weaker. The first, lower temperature degradation is characterised by the primary pyrolysis of the more accessible sulphated regions (Roman and Winter 2004) where the sulphuric acid acts as a dehydrating catalyst on the cellulose (Kim et al. 2001). It is suggested that the subsequent slower process is due to charring of the solid residue resulting from the dehydration step (Wang et al. 2007).
After grafting on the sulphate groups, the onset of thermal degradation shifted from $154{ }^{\circ} \mathrm{C}$ for the unmodified to $240-250{ }^{\circ} \mathrm{C}$ for the modified samples. This may be explained by the removal of the acidic hydrogen associated with the sulphate group, which facilitates the acid-catalyzed dehydration process. The hydrogen is removed through grafting of the azetidinium substituents. Wang et al. (2007) showed that by replacing the hydrogen ion associated with the sulphate groups with a sodium ion, the acid catalysed dehydration was inhibited. There were no greater differences between the modified CNC in this respect, although the onset temperature was $10^{\circ} \mathrm{C}$ higher for CNC-MorphOMe-Az than for CNC- diAllylOMe-Az. The minor weight loss at temperatures below $100{ }^{\circ} \mathrm{C}$ is associated with evaporation of water from the cellulose. The difference in remaining char, which is greater for the unmodified CNC than for the modified samples, can be attributed to the dehydrating action of the sulphate groups which results in a more oxygendeficient char that is less prone to form volatiles (Kim et al. 2001). Wang et al. (2007) showed that the char decreases when the acidic hydrogen is removed, which may suggest that there are different reaction pathways in the pyrolysis that occur during the TGA measurement.

Rheological properties of dispersion based on modified CNC

The rheological properties of the dispersions were determined at concentrations of 0.65 and $1.3 \mathrm{wt} \%$ (weight-\%). The $\mathrm{pH}$-values of the dispersions at which the rheological measurements were performed are given in Table 1. The lowest $\mathrm{pH}$-values were noted for the unmodified $\mathrm{CNC}$ which most likely can be attributed to sulphate groups left on the cellulose surface after the hydrolysis. The dispersion containing CNC-MorphOMe displayed a somewhat lower $\mathrm{pH}$ value, at least at the lower concentration, than the other two dispersions containing modified CNC. It was in most cases slightly higher than $\mathrm{pH} 5$.

Figure 4 shows the shear viscosity of the CNCdispersions as functions of the shear rate in the region from 1 to $1000 \mathrm{~s}^{-1}$. The concentration was here $1.3 \mathrm{wt} \%$. At low shear rates $\left(<50 \mathrm{~s}^{-1}\right)$, the unmodified CNC-dispersion exhibited the lowest shear viscosity, followed by the dispersion containing CNC-diHexylOMe, that based on CNC-MorphOMe 
Table 1 The $\zeta$-potential (standard deviation in parentheses) of the CNC-particles at a concentration of $0.05 \mathrm{wt} \%$ and $\mathrm{pH} 3.5$, the content of sulphate half esters on the surfaces of the CNC and the $\mathrm{pH}$-values of the different dispersions at the two concentrations used for the rheological characterization

\begin{tabular}{lllll}
\hline Type of CNC & $\zeta$-potential $(\mathrm{mV})$ & Sulphate half ester content $(\mu \mathrm{mol} / \mathrm{g})$ & $\mathrm{pH}$ at $0.65 \mathrm{wt} \%$ & $\mathrm{pH}$ at $1.3 \mathrm{wt} \%$ \\
\hline CNC-unmod. & $-71.7(2.0)$ & 350.4 & 2.7 & 2.3 \\
CNC-Morph-OMe & $-45.6(2.4)$ & 101.8 & 4.4 & 5.0 \\
CNC-diHexyl-OMe & $-54.2(2.0)$ & 179.9 & 5.2 & 5.3 \\
CNC-diAllyl-OMe & $-47.9(1.9)$ & 118.7 & 5.2 & 5.0 \\
\hline
\end{tabular}

Fig. 3 Thermogravimetric curves showing the thermal degradation of the unmodified $\mathrm{CNC}$ and of the azetidinium-grafted $\mathrm{CNC}$

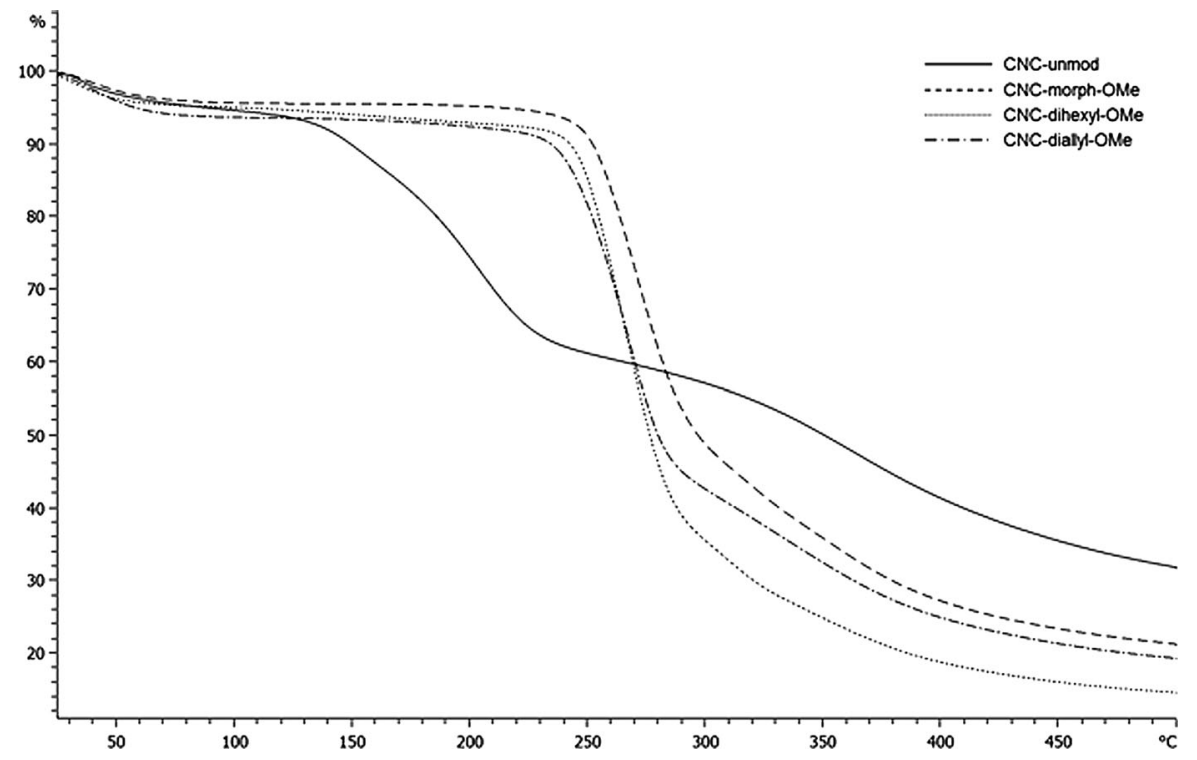

Table 2 The temperature at the onset of degradation and the residual char content for the unmodified as well as the grafted $\mathrm{CNC}$

\begin{tabular}{lll}
\hline Type of CNC & $T_{\text {onset }}\left({ }^{\circ} \mathrm{C}\right)$ & Residual char content $(\mathrm{wt} \%)$ \\
\hline CNC-unmod. & 157 & 32 \\
CNC-Morph-OMe & 250 & 21 \\
CNC-diHexyl- & 246 & 14 \\
$\quad$ OMe & & \\
CNC-diAllyl-OMe & 242 & 19 \\
\hline
\end{tabular}

and finally the one containing CNC-diAllylOMe, which thus exhibited the highest viscosity.

All the dispersions exhibited a pronounced shearthinning behaviour and the curves approached each other to some extent at higher shear rates (and even crossed each other). Viscosity relations of this type are often fitted to the simple power law
$\eta=K(\dot{\gamma})^{n-1}$

where $\eta$ is the shear viscosity, $\dot{\gamma}$ the shear rate and $K$ and $n$ are often called the consistency and the flow index, respectively. Equation (1) was fitted to the experimental results (although a perfect fit was not obtained) and in the case of the unmodified CNCdispersion, the flow index $n$ was about 0.8 , whereas the dispersions containing the grafted $\mathrm{CNC}$ exhibited $n$ values in the range $0.3-0.35$ at a concentration of $0.65 \mathrm{wt} \%$. The unmodified dispersion thus showed a more Newtonian character (n closer to 1 and see Fig. 4) than the others. The viscosity increased, as expected, with increasing CNC-concentration (Karppinen et al. 2011; Moberg et al. 2017; Pääkkö et al. 2007). In the case of the dispersions containing unmodified $\mathrm{CNC}$ and CNC-diAllylOMe, the flow index decreased, i.e. the dispersions became more 
Fig. 4 The shear viscosity of the CNC-dispersions at a concentration of $1.3 \mathrm{wt} \%$ as a function of the shear rate

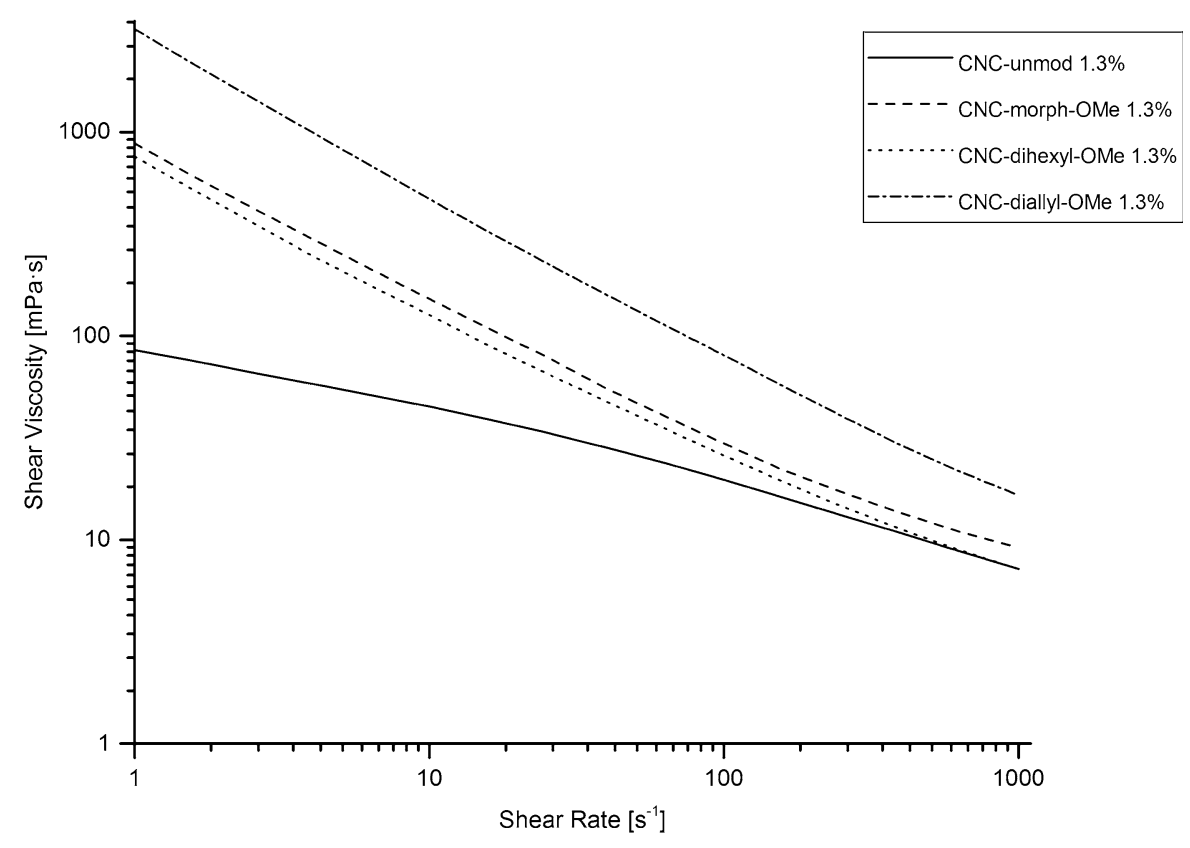

shear-thinning in character, which is not unrealistic (Moberg et al. 2016). For the other two dispersions based on the modified CNC there was virtually no change in the flow index when the concentration was increased from 0.65 to $1.3 \mathrm{wt} \%$. The viscosity curves were quite smooth, and there were no clearly different regions in the curves, as noted by Shafiei-Sabet et al. (2012), that would have indicated the formation of chiral nematic liquid crystalline structures. It may be that the concentration of the CNC was too low in the present studies for such a formation to take place.

As pointed out by Moberg et al. (2017), it is not straightforward to compare the rheological properties of CNC dispersions reported in the literature, since different preparation techniques and raw materials are reflected in the surface character and particle dimensions which in turn have a clear impact on the flow behaviour of suspensions. It may however be noted that Shafiei-Sabet et al. (2013) measured the shear viscosity of $\mathrm{CNC}$ dispersions (produced by sulphuric acid hydrolysis) of different concentrations. For a well-dispersed (sonicated) dispersion with a concentration of $1 \mathrm{wt} \%$, they reported a shear viscosity of about $100 \mathrm{mPas}$ at $0.1 \mathrm{~s}^{-1}$ which was reduced to slightly more than $10 \mathrm{mPas}$ when increasing the shear rate to $100 \mathrm{~s}^{-1}$. These values are not too different from the viscosities measured for the unmodified CNCdispersion shown in Fig. 4. Values for shear viscosity in the same range are also given in the review by Oguzlu et al. (2017) for a dispersion softwood kraft sulfonated CNC at a concentration of $1.33 \mathrm{vol} \%$. As already noted from the work of Hasani et al. (2008), surface functionalization can result in a significant increase of the viscosity, which in a sense parallels the enhancement in viscosity obtained with the grafted azetidinium salts, Fig. 4.

The dynamic-mechanical analysis showed that the samples that exhibited the highest shear viscosity also had the highest storage moduli, as shown in Fig. 5. The solids content of the $\mathrm{CNC}$ in this case was also $1.3 \mathrm{wt} \%$.

All the curves approached a plateau at low shear strains corresponding to the linear viscoelastic region, which appears to be shorter for the dispersions based on CNC-MorphOMe and CNC-diAllylOMe (of the order $10 \%$ or lower). In the case of the unmodified $\mathrm{CNC}$, the loss modulus was higher than the storage modulus at the plateau, indicating that the material was more liquid-like. The situation was the opposite for the other three dispersions, i.e. the storage modulus was greater than the loss modulus, indicating a more gel-like behaviour. This may be interpreted as indicating that the grafting of the chemical groups has improved the ability of the dispersions to form a network structure. The CNC-diAllylOMe dispersion exhibited the highest storage modulus; more than two 
Fig. 5 Dynamicmechanical properties of the $\mathrm{CNC}$ dispersions as a function of the applied strain amplitude at $25^{\circ} \mathrm{C}$. The frequency was $1 \mathrm{~Hz}$ and the CNC-concentration $1.3 \mathrm{wt} \%$

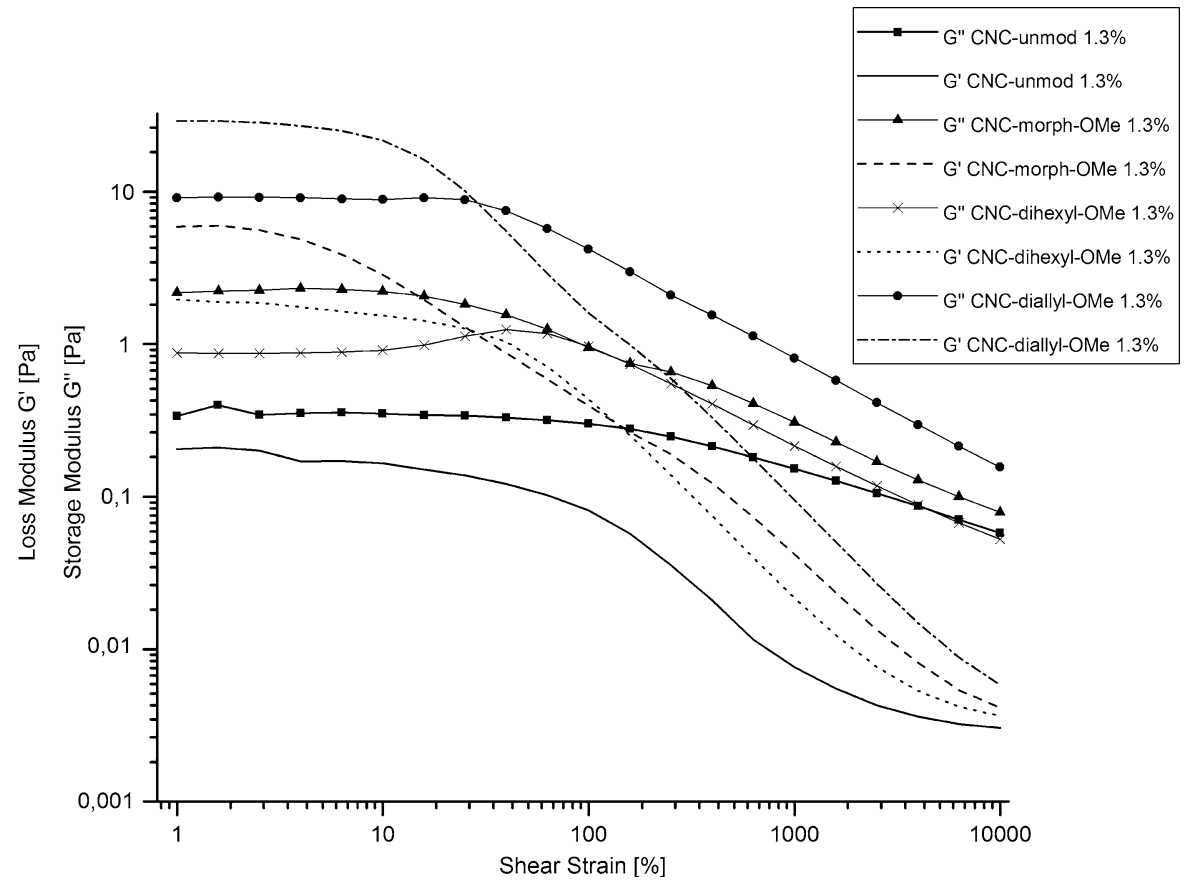

decades higher than that of the dispersion containing the unmodified CNC. There was a tendency that the stiffer the dispersion, the lower was the strain it could sustain before the structure broke down, i.e. the shorter was the linear viscoelastic region. It can also be noted (see Fig. 5) that the storage (and loss) moduli values of the four dispersions seemed to converge to a similar level at large strains.

Comparison of the model dispersions and the dispersions based on the modified CNC

Figure 6 shows the shear viscosity as a function of the shear rate for dispersions based on unmodified CNC, $\mathrm{CNC}$ with grafted MorphOMe and diHexylOMe and dispersions of $\mathrm{CNC}$ with the corresponding compounds added in the aqueous phase but not grafted to the cellulose surface. The concentration in this case was $1.3 \mathrm{wt} \%$. When the chemical groups were not grafted to the $\mathrm{CNC}$, there was no increase in the viscosity level. The viscosity in fact decreased somewhat when the $\gamma$-N,-morpholino- $\beta$-methoxypropyl or $\gamma$-N,N-dihexylamino- $\beta$-methoxypropyl substituents were added compared to that of the dispersions containing the unmodified $\mathrm{CNC}$, which indicates a change in the interaction between the particles. Thus, the chemical groups must be grafted to the $\mathrm{CNC}$ in

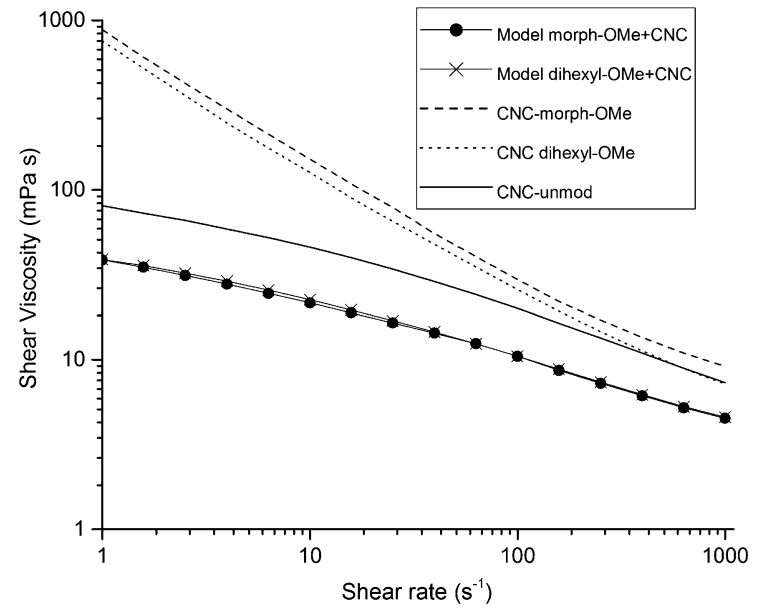

Fig. 6 The shear viscosity as function of the shear rate for unmodified $\mathrm{CNC}$ dispersions, for dispersions of modified CNC and for dispersions where the chemical groups were not grafted to the CNC surfaces. The concentration was $1.3 \mathrm{wt} \%$

order to appreciable increase the viscosity of the dispersions.

The large increase in shear viscosity and dynamic moduli upon grafting, seemingly leading to an improved ability of the dispersion to form a network structure may be explained by the molecular interactions of the introduced substituents. The grafted azetidinium salts are primarily lipophilic 
compounds and thus not very prone to an attractive interaction with water. In an effort to minimize contact with water, the substituents preferentially interact with each other thus forming a network. The strength of this network is dependent on the strength of the intermolecular bonding of the substituents. It is probable that this type of bonding between substituents grafted onto CNC particles is responsible for the network formation and the strong effect on the rheological properties of the dispersions. The dominating molecular interaction between alkyl groups is van der Waals forces, and this applies to the MorphOMe and diHexylOMe substituents. The length of the functional groups can perhaps explain the difference in shear viscosity, as the MorphOMe is a smaller, stiffer compound than the longer, more flexible diHexylOMe. Since the diHexylOMe has more conformational freedom, the network is more flexible, thus lowering the shear viscosity. The significantly higher shear viscosity of diAllylOMe may be associated with a stronger molecular interaction acting between the substituents, as a result of the $\pi$-bonds of the allyl functionality. Stacking of $\pi-$ $\pi$-bonds is a very strong type of intermolecular bonding and results in a stiff network, as the conformational freedom is low.
The gel concentration

The concentration at which the dispersion forms a gel can be estimated by determining the concentration at which the storage and loss moduli overlap over an appreciable measurement range, cf Shafiei-Sabet et al. (2013) who used the similarity over a range of frequencies. Figure 7 shows the storage and loss moduli as functions of the applied strain amplitude for unmodified CNC dispersions of different concentrations $(1.5,2.0$ and $2.5 \mathrm{wt} \%)$. Judging from the figure, the gel point is ca $2.5 \mathrm{wt} \%$. Similar experiments were performed with the dispersions containing the modified CNC. Due to the low values of the moduli at low CNC-concentrations, these measurements were subject to an appreciable scatter, but it was estimated that the gel points were in the range 0.2 to $0.4 \mathrm{wt} \%$, i.e. significantly lower than that of the unmodified CNC elements. Thus, it is not surprising that the rheological properties are enhanced for the modified dispersions as revealed by a relatively high shear viscosity and increased dynamic moduli.

It is known the that formation of a gel (or a percolating network) has a strong influence on the rheological properties of the system (Kim and Macosko 2009; Kotsilkova 2007; Oxfall et al. 2015).
Fig. 7 The storage and loss moduli as functions of the applied strain amplitude for dispersions based on unmodified $\mathrm{CNC}$ with concentrations of $1.5,2.0$ and $2.5 \mathrm{wt} \%$. The frequency was $1 \mathrm{~Hz}$

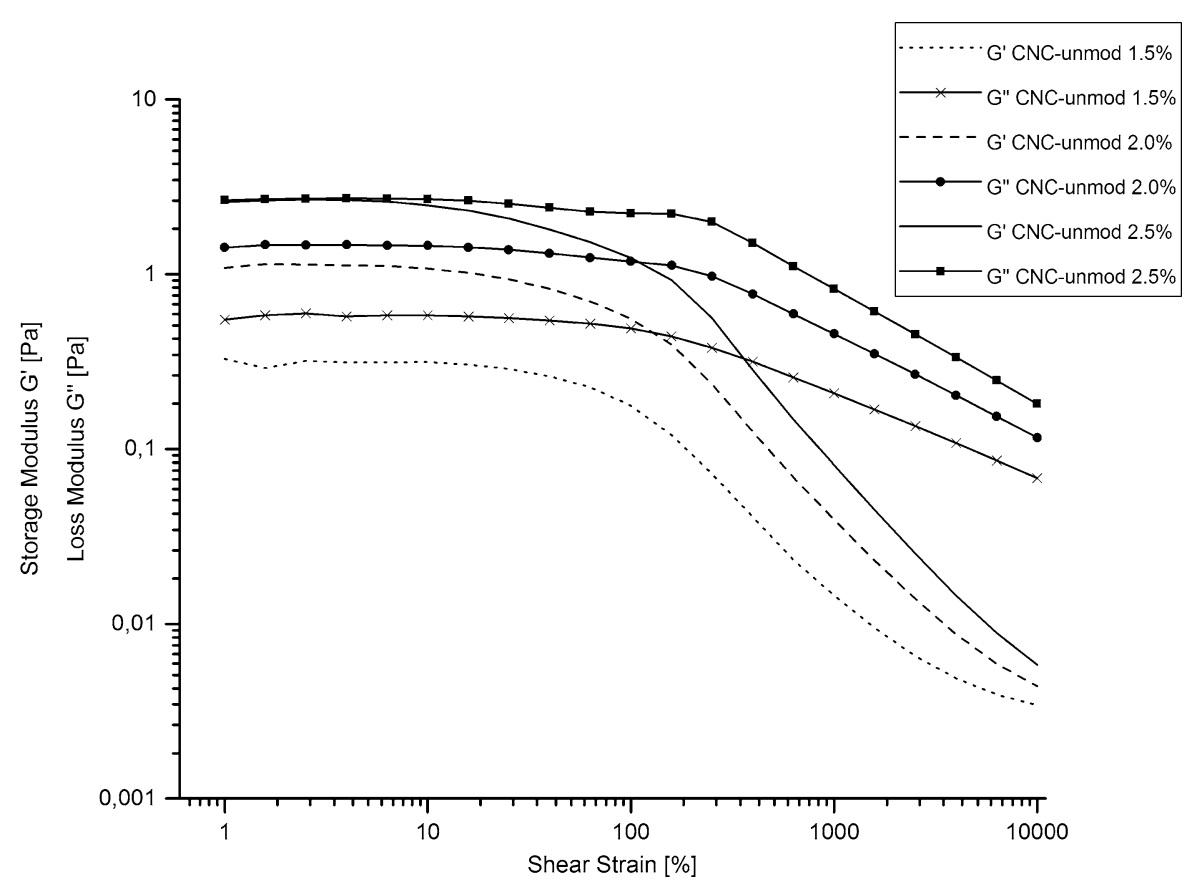


The percolation threshold $\left(\varphi_{c}\right)$ can be estimated using different approaches. For example, Xu et al. (2013) used

$\varphi_{c}=0.7 \frac{\mathrm{w}}{\mathrm{L}}$

in order to estimate the onset of percolation in terms of a volume fraction. Here $w$ is the width (diameter) of the elements and $L$ their length. In principle Eq. (2) does not account for interactions between the elements due to charges, grafted groups etc. and flow-induced orientation and, furthermore, other values of the numerical constant have been suggested, see e.g. (Hill 2008). With these limitations and reservations, the gel concentration could be estimated using the measured average values of the dimensions reported by (Moberg et al. 2017) to be $1.99 \mathrm{vol} \%$. In the case of the dispersion based on unmodified $\mathrm{CNC}$, the experimental value of the gel point was about $1.7 \mathrm{vol} \%$ (2.5 wt \%), assuming a density of cellulose of $1.5 \mathrm{~g} /$ $\mathrm{cm}^{3}$ and of water of $1.0 \mathrm{~g} / \mathrm{cm}^{3}$. Considering the limitations of the approach, the experimental value is quite close to the theoretical estimate.

The dynamic-mechanical measurements described above clearly show that the grafting of chemical groups has a strong effect on the gel point. The experimental value is significantly lower than the "theoretical" value of $1.99 \mathrm{vol} \%$. This is not unexpected since interaction effects between the grafted elements are not taken into consideration in the above approach. The hydrophobic attractive interactions between the grafted substituents obviously lead to a lowering of the percolation threshold, cf also (Safran et al. 1985), which appears plausible. This does not imply that the nanocrystals themselves are in physical contact with each other at such a low concentration, but that the $\mathrm{CNC}$, which constitute the reinforcing elements, forms a coherent network at the gel point through the mutual interaction of the hydrophobic substituents grafted onto the nanoparticles.

\section{Conclusions}

FTIR spectroscopy, supported by measurements of the $\zeta$-potential, showed that azetidinium salts could be grafted onto the sulphate ester groups of the CNC surfaces. This surface modification of the $\mathrm{CNC}$ particles is manifested through a dramatic shift in the temperature for the onset of thermal degradation of the nanocellulosic particles. The improvement in thermal resistance is here attributed to a removal of acidic hydrogen associated with the sulphate groups.

Furthermore, it was shown that the grafting of the azetidinium salts onto the $\mathrm{CNC}$ had a strong effect on the shear viscosity and on the viscoelastic properties of aqueous dispersions of CNC. Both the shear viscosity (especially at lower shear rates) and the dynamicmechanical moduli $G^{\prime}$ and $G^{\prime \prime}$ increased markedly compared to the values for unmodified CNC. The magnitudes of the viscosity and of the moduli depended on the type of azetidinium salt used. This increase in the rheological parameters was paralleled by a simultaneous decrease in the gel point (percolation threshold) of the dispersions. It is suggested that the pronounced changes in rheological behaviour due to the surface modification can be associated with hydrophobic attractive interactions between the grafted substituents. A more hydrophobic character of the CNC surfaces could be beneficial when using $\mathrm{CNC}$ as reinforcing elements in a polymer matrix composite.

Acknowledgments The authors thank the Wallenberg Wood Science Center, the Swedish Research Council Formas and Chalmers University of Technology for financial support. Dr J. A. Bristow is gratefully acknowledged for the linguistic revision of the manuscript.

Open Access This article is distributed under the terms of the Creative Commons Attribution 4.0 International License (http:// creativecommons.org/licenses/by/4.0/), which permits unrestricted use, distribution, and reproduction in any medium, provided you give appropriate credit to the original author(s) and the source, provide a link to the Creative Commons license, and indicate if changes were made.

\section{References}

Ahola S, Österberg M, Laine J (2008) Cellulose nanofibrilsadsorption with poly(amideamine) epichlorohydrin studied by QCM-D and application as a paper strength additive. Cellulose 15:303-314. https://doi.org/10.1007/s10570007-9167-3

Aloulou F, Boufi S, Beneventi D (2004) Adsorption of organic compounds onto polyelectrolyte immobilized-surfactant aggregates on cellulose fibers. J Colloid Interface Sci 280:350-358. https://doi.org/10.1016/j.jcis.2004.08.008

Beck-Candanedo S, Roman M, Gray DG (2005) Effect of reaction conditions on the properties and behavior of wood 
cellulose nanocrystal suspensions. Biomacromol 6:1048-1054. https://doi.org/10.1021/bm049300p

Bercea M, Navard P (2000) Shear dynamics of aqueous suspensions of cellulose whiskers. Macromolecules 33:6011-6016. https://doi.org/10.1021/ma000417p

Börjesson M, Westman G (2016) Branching of hemicelluloses through an azetidinium salt ring-opening reaction. Carbohydr Res 428:23-30. https://doi.org/10.1016/j.carres.2016. 04.005

Brydson JA (1999) Plastics materials, 7th edn. ButterworthHeinemann, Oxford

Chattopadhyay S, Keul H, Moeller M (2012) Functional polymers bearing reactive azetidinium groups: synthesis and characterization. Macromol Chem Phys 213:500-512. https://doi.org/10.1002/macp.201100480

Chauve GFC, Jean B (2014) Bionanomaterials: separation processes, characterization and properties. In: Oksman KMA, Bismark A, Rojas O, Sain M (eds) Handbook of green materials, vol 1. World Scientific Publishing Co, Singapore, pp 73-87

Chen G, Zhang B, Zhao J, Chen H (2013) Improved process for the production of cellulose sulfate using sulfuric acid/ ethanol solution. Carbohydr Polym 95:332-337. https:// doi.org/10.1016/j.carbpol.2013.03.003

Ciolacu D, Ciolacu F, Popa VI (2011) Amorphous cellulosestructure and characterization. Cellulose Chem Technol 45:13-21

Cranston ED, Gray DG (2006) Morphological and optical characterization of polyelectrolyte multilayers incorporating nanocrystalline cellulose. Biomacromol 7:2522-2530. https://doi.org/10.10217/bm0602886

Dong XM, Gray DG (1997) Effect of counterions on ordered phase formation in suspensions of charged rodlike cellulose crystallites. Langmuir 13:2404-2409. https://doi.org/ $10.1021 / 1 \mathrm{a9} 60724 \mathrm{~h}$

Espy HH (1995) The mechanism of wet-strength development in paper: a review. Tappi J 78(4):90-99

Gaertner VR (1968) Ring-opening alkylations of 1,5-dialkyl-3substituted azetidinium cations. Substituent entropy-controlled strained ring-chain equilibria. J Org Chem 33:523-530. https://doi.org/10.1021/jo01266a010

Gårdebjer S, Andersson M, Engström J, Restorp P, Persson M, Larsson A (2016) Using Hansen solubility parameters to predict the dispersion of nanoparticles in polymeric films. Polym Chem 7:1756-1764. https://doi.org/10.1039/ C5PY01935D

Gurziy V, Tyumentseva OS, Britvin SN, Krivoichev SV, Tananaev IG (2018) Ring opening of azetidine cycle: first examples of 1 -azetidinepropanamine molecules as templates in hybrid organic-inorganic compounds. J Mol Struct 1151:88-96. https://doi.org/10.1016/j.molstruc.2017.09.042

Hasani M, Cranston ED, Westman G, Gray DG (2008) Cationic surface functionalization of cellulose nanocrystals. Soft Matter 4:2238-2244. https://doi.org/10.1039/b806789a

Herrera MA, Mathew AP, Oksman K (2012) Comparison of cellulose nanowhiskers extracted from industrial bio-residue and commercial microcrystalline cellulose. Mater Lett 71:28-31. https://doi.org/10.1016/j.matlet.2011.12.011

Hill RJ (2008) Elastic modulus of microfibrillar cellulose gels. Biomacromolecules 9:2963-2966. https://doi.org/10.1021/ bm800490x
Karppinen A, Vesterinen A-H, Saarinen T, Pietikäinen P, Seppälä J (2011) Effect of cationic polymethacrylates on the rheology and flocculation of microfibrillated cellulose. Cellulose 18:1381-1390. https://doi.org/10.1007/s10570011-9597-9

Kim H, Macosko CW (2009) Processing-property relationships of polycarbonate/graphene composites. Polymer 50:3797-3809. https://doi.org/10.1016/j.polymer.2009.05.038

Kim D-Y, Nishiyama Y, Wada M, Kuga S (2001) High-yield carbonization of cellulose by sulfuric acid impregnation. Cellulose 8:29-33. https://doi.org/10.1023/a:101662110 3245

Klemm D, Kramer F, Moritz S, Lindström T, Ankerfors M, Gray D, Dorris A (2011) Nanocelluloses: a new family of naturebased materials. Angew Chem Int Ed 50:5438-5466. https://doi.org/10.1002/anie.201001273

Kotsilkova R (2007) Thermoset nanocomposites for engineering applications. Smithers Rapra Technology, Shrewsbury

Lee K-Y, Aitomäki Y, Berglund LA, Oksman K, Bismarck A (2014) On the use of nanocellulose as reinforcement in polymer matrix composites. Compos Sci Technol 105:15-27. https://doi.org/10.1016/j.compscitech.2014. 08.032

Moberg T, Tang H, Zhou Q, Rigdahl M (2016) Preparation and viscoelastic properties of composite fibres containing cellulose nanofibrils: formation of a coherent fibrillar network. J Nanomater. https://doi.org/10.1155/2016/9569236

Moberg T, Sahlin K, Yao K, Geng S, Westman G, Zhou Q, Oksman K, Rigdahl M (2017) Rheological properties of nanocellulose suspensions: effects of fibril/particle dimensions and surface characteristics. Cellulose 24:2499-2510. https://doi.org/10.1007/s10570-0171283-0

Moon RJ, Martini A, Nairn J, Simonsen J, Youngblood J (2011) Cellulose nanomaterials review: structure, properties and nanocomposites. Chem Soc Rev 40:3941-3994. https:// doi.org/10.1039/C0CS00108B

Obokata T, Isogai A (2007) The mechanism of wet-strength development of cellulose sheets prepared with polyamideamine-epichlorohydrin (PAE) resin. Colloids Surf A 302:525-531. https://doi.org/10.1016/j.colsurfa.2007.03. 025

Oguzlu H, Danumah C, Boluk Y (2017) Colloidal behavior of aqueous cellulose nanocrystal suspensions. Curr Opin Colloid Interface Sci 29:46-56. https://doi.org/10.1016/j. cocis2017.02.002

Oxfall H, Ariu G, Gkourmpis T, Rychwalski RW, Rigdahl M (2015) Effect of carbon black on electrical and rheological properties of graphite nanoplatelets/poly(ethylene-butyl acrylate) composites. Expr Polym Lett 9:66-76. https://doi. org/10.3144/expresspolymlett.2015.7

Pääkkö M et al. (2007) Enzymatic hydrolysis combined with mechanical shearing and high-pressure homogenization for nanoscale cellulose fibrils and strong gels. Biomacromol 8:1934-1941. https://doi.org/10.1021/bm061215p

Rånby BG (1951) Fibrous macromolecular systems. Cellulose and muscle. The colloidal properties of cellulose micelles. Discuss Faraday Soc 11:158-164. https://doi.org/10.1039/ DF9511100158

Roman M, Winter WT (2004) Effect of sulfate groups from sulfuric acid hydrolysis on the thermal degradation 
behavior of bacterial cellulose. Biomacromol 5:1671-1677. https://doi.org/10.1021/bm034519+

Safran SA, Webman I, Grest GS (1985) Percolation in interacting colloids. Phys Rev A 32:506-511. https://doi.org/ 10.1103/PhysRevA.32.506

Shafiei-Sabet S, Hamad WY, Hatzikiriakos SG (2012) Rheology of nanocrystalline cellulose aqueous suspensions. Langmuir 28:17124-17133. https://doi.org/10.1021/ la303380v

Shafiei-Sabet S, Hamad WY, Hatzikiriakos SG (2013) Influence of degree of sulfation on the rheology of cellulose nanocrystal suspensions. Rheol Acta 52:741-751. https:// doi.org/10.1007/s00397-013-0722-6

Shishlov NM, Khursan SL (2016) Effect of ion interactions on the IR spectrum of benzenesulfonate ion. Restoration of sulfonate ion symmetry in sodium benzenesulfonate dimer. J Mol Struct 1123:360-366. https://doi.org/10.1016/j. molstruc.2016.06.030
Siqueira EJ, Salon M-CB, Belgacem MN, Mauret E (2015) Carboxymethylcellulose (CMC) as a model compound of cellulose fibers and polyamideamine epichlorohydrin (PAE)-CMC interactions as a model of PAE-fibers interactions of PAE-based wet strength papers. J Appl Polym Sci 132(26):42144. https://doi.org/10.1002/app-42144

Wang N, Ding E, Cheng R (2007) Thermal degradation behaviors of spherical cellulose nanocrystals with sulfate groups. Polymer 48:3486-3493. https://doi.org/10.1016/j. polymer.2007.03.062

Xu X, Liu F, Jiang L, Zhu JY, Haagenson D, Wiesenborn DP (2013) Cellulose nanocrystals vs. cellulose nanofibrils: a comparative study on their microstructures and effects as polymer reinforcing agents. ACS Appl Mater Interfaces 5:2999-3009. https://doi.org/10.1021/am302624t 